\title{
LANDSAT 8 VE SENTINEL-2 UYDU GÖRÜNTÜLERİ İLE BÖLGESEL ORTALAMA BULUTLULUK TESPITI
}

\author{
Kaan KALKAN \\ Dr. TÜBİTAK Uzay Teknolojileri Araştırma Enstitüsü, 06800, Ankara, kaan.kalkan@tubitak.gov.tr
}

\begin{abstract}
ÖZET
Ücretsiz olarak servis edilen Landsat serisi uydular ve bu seriye güçlü bir şekilde eklenen Sentinel serisi uydular ile kullanıcılar yüksek zamansal çözünürlüklü uzaktan algılama görüntülerine ulaşarak hızla artan bir şsekilde birçok farklı alanda çalı̧̧malar yapmaktadır. Artan zamansal çözünürlüğe rağmen farklı meteorolojik özelliklere sahip bölgelerde uydu görüntülerinde bulunan bulutlar yapılan çalışmaları kısıtlamaktadır. Birçok uzaktan algılama çalışması için ticari uydu görüntüsü siparişi öncesinde ilgili bölgenin bulutluluk oranı incelenerek bulutsuz bir zaman için planlama yapılmaya çalı̧̧ılmaktadır. Ücretsiz olarak servis edilen ve 30 yıldan fazla bir zamana yayılmış bu verilerin metadata bilgileri ilgili bölgeler için hangi zamanda, ne kadarlık bulut oranına sahip görüntüler elde edildiği bilgisine ulaşılabilmektedir. Bu çallşmada iş bu veriler kullanılarak her hangi bir zaman veya mevsim aralı̆ğnda görüntü alınması veya ilgili çalışmalarda görüntü kullanılması planlanan bölgeler için ortalama bulutluluk verisi bu metadata bilgileri kullanılarak üretilmiştir.
\end{abstract}

Anahtar Sözcükler: bulutluluk oranı, Landsat 8, Sentinel-2, uzaktan algılama, metadata

\section{REGIONAL AVERAGE CLOUDNESS CALCULATION USING LANDSAT 8 AND SENTINEL-2 IMAGERY}

Different applications of remote sensing are increasing day by day by using freely available Landsat satellite series and Sentinel series which have high temporal resolution. Although high temporal resolution, cloud cover limits studies where have different meteorological conditions. Many different satellite operators use cloud cover data to plan new acquisitions. Metadata information of freely available 30 years of satellite imagery can be used to identify and analyze cloud cover of different regions. In this study, these metadata information is used to analyze calculation of average cloud cover rates for different months and sesasons.

Keywords: cloud cover, Landsat 8, Sentinel-2, remote sensing, metadata

\section{GİRIS}

USGS (United States Geological Survey) tarafından işletilen Landsat serisi uydular en uzun süreli uzaktan algılama veri arşivi olarak karşımıza çıkmaktadır. Sentinel serisi uydular ile bu arşiv Sentinel serisi uyduların sahip olduğu yüksek zamansal çözünürlük ile güçlenmektedir. Bu iki verinin ortak kullanımını sağlamak üzere bir çok araştırma yapılmaktadır (NASA, 2018). Bu iki veri birbirini tamamlar nitelikte bir çok çalışma için girdi sağlayacaktır.

Yüksek zamansal çözünürlüğe ihtiyaç olan çalışmalarda hangi günlerde çekilen verilerin kullanılacağı sorusu önem taşımaktadır. Bu çalışmada;

- Her mevsim için ortalama bulutluluk

- Her ay için ortalama bulutluluk

- $\quad$ Ülke geneli için ortalama bulutluluk

- İlgili Enlem-Boylam aralığı için ortalama bulutluluk

gibi analizler Landsat serisi ve Sentinel serisi uydu görüntülerinin sahip olduğu metadata bilgileri ile hesaplanmıştır.

\section{YÖNTEM}

Ücretsiz servis edilen Landsat ve Sentinel görüntüleri, Amazon Cloud ve Google Cloud servislerinden indirilebilmektedir. Bu görüntülerin hepsini indirip, tüm bu görüntülerde bulut belirleme algoritmalarının (Kalkan ve Maktav, 2017) koşturulması sonucu oluşacak hesaplama iş gücü çok yüksek olacağından, bu veriler ile birlikte sunulan metadata dosyalarında bulunan bulut oranı bilgisi ile çalışma gerçekleştirilmiştir. Geçmişten günümüze birçok uydu görüntüsünün oluşturduğu arşiv düşünülürse dünyanın herhangi bir bölgesi için ilgilenilen zamanda 
daha önce çekilmiş görüntülerin oluşturduğu veri setinden ilgili bölgede hangi oranda bulutluluk oluşacağ ile ilgili ön bilgi elde edilebilecektir. 2008 yılında benzer bir çalışma Amerika Birleşik Devletleri özelinde ve dünya ölçeğinde Ju ve Roy tarafindan gerçekleştirilmiştir (2008).

Landsat 8 görüntülerinden bulutların belirlenmesinde birden fazla yöntem kullanılmaktadır. Bu yöntemler USGS (Birleşik Devletler Jeoloji Kurumu) tarafından, ACCA, See-5 CCA, Cirrus CCA ve AT-ACCA olarak listelenmiştir (USGS, 2018). Sentinel-2 görüntülerinden ise Seviye 2A görüntünün üretilmesi sırasında Scene Classification (SC) bölümü içerisinde ayrıntılı bir bulut belirleme algoritması çalıştırılmaktadır (ESA, 2018).

Çalışma Türkiye sınırlarını kapsayan görüntüler ile gerçekleştirilmiştir. Yazılan kod bloğu ile bulut servislerden Türkiye sınırlarına giren Landsat ve Sentinel görüntülerine ait metadata verilerinin tümü indirilerek istatiksel olarak her bölge için ortalama bulut oranı yüzdeleri hesaplanmıştır (Şekil 1-2).

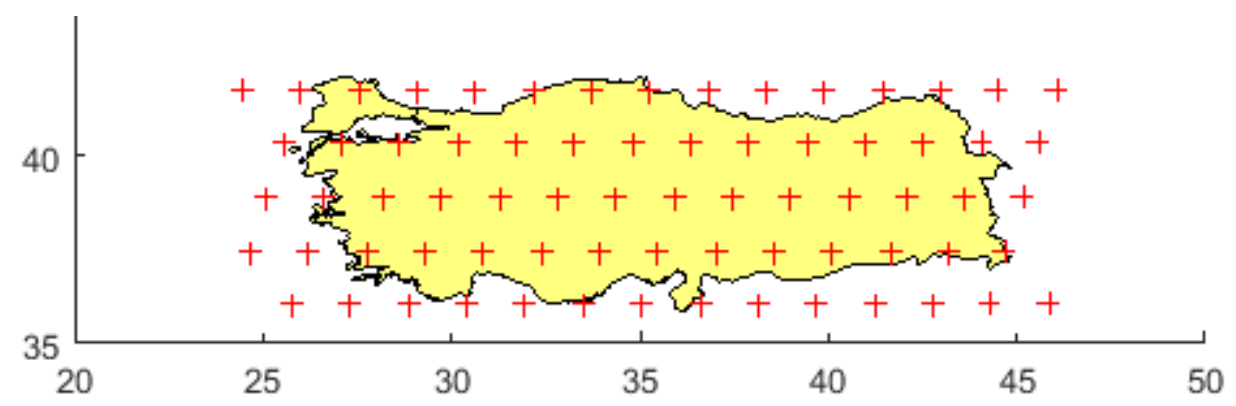

Şekil 1. Landsat path-row’larının Türkiye sınırlarına giren merkez koordinatları.

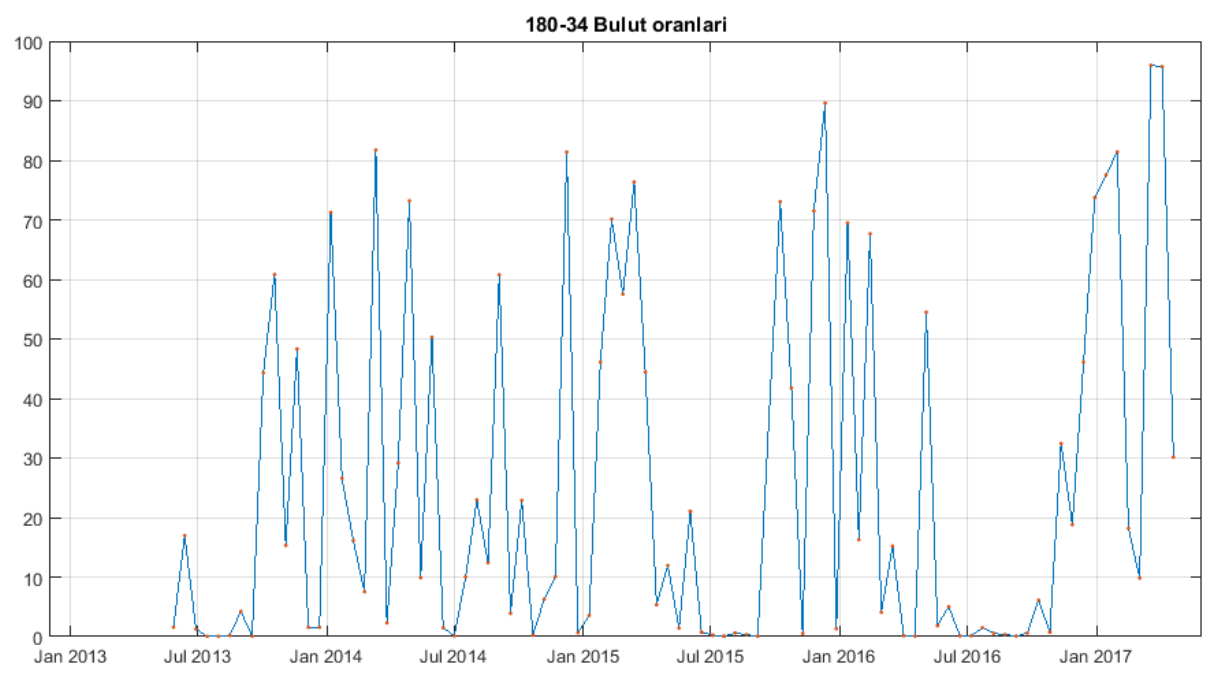

Şekil 2. Örnek olarak 180-34 path-row'una ait Landsat-8 verisinin 4 yıllık bulut verisi.

$\mathrm{Bu}$ verilerin oluşturduğu veri tabanı mekânsal olarak Landsat path-row'ları şeklinde CBS (Coğrafi Bilgi Sistemleri) ortamında görselleştirilmiştir. Aylar özelinde ortalama bulutluluk yüzdeleri Çizelge 1'de ve grafiği Şekil 3'te verilmiştir. Mevsimler özelinde İlkbahar - Yaz - Sonbahar - Kış ortalama bulutluluk yüzdeleri Çizelge 2’de, haritaları ise Şekil 4-7'de verilmiştir. 
Çizelge 1. Aylara göre Türkiye Landsat 8 uydu görüntülerinin ortalama bulut oranları.

\begin{tabular}{|l|l|}
\hline Ocak & 46.2 \\
\hline Şubat & 44.01 \\
\hline Mart & 44.09 \\
\hline Nisan & 33.46 \\
\hline Mayıs & 29.24 \\
\hline Haziran & 18.5 \\
\hline Temmuz & 11.8 \\
\hline A ğustos & 11.6 \\
\hline Eylül & 17.7 \\
\hline Ekim & 31.8 \\
\hline Kasım & 33.9 \\
\hline Ocak & 46.2 \\
\hline
\end{tabular}

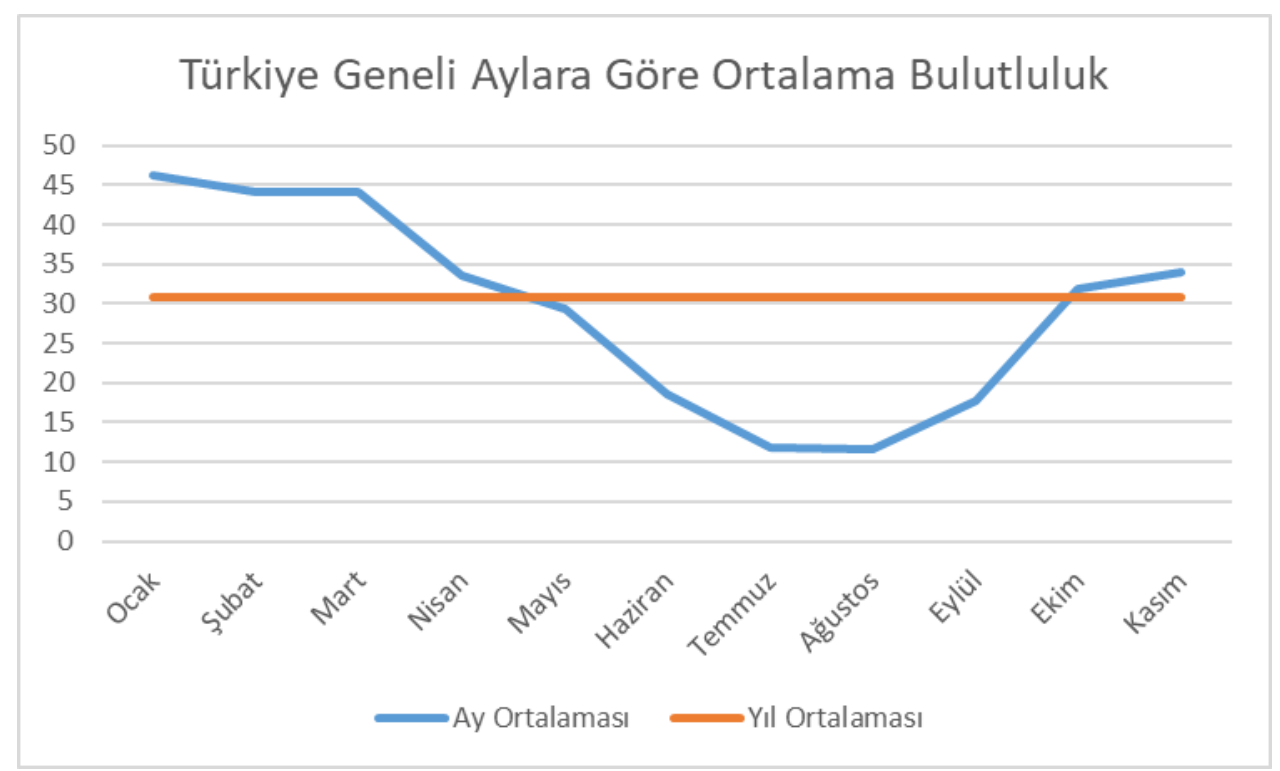

Şekil 3. Türkiye geneli aylara göre ortalama bulutluluk grafiği .

Çizelge 2. Mevsimlere göre Türkiye Landsat 8 uydu görüntülerinin ortalama bulut oranları.

\begin{tabular}{|l|l|l|l|}
\hline İlkbahar & Kiş & Sonbahar & Yaz \\
\hline 35.6 & 45.8 & 27.8 & 14 \\
\hline
\end{tabular}

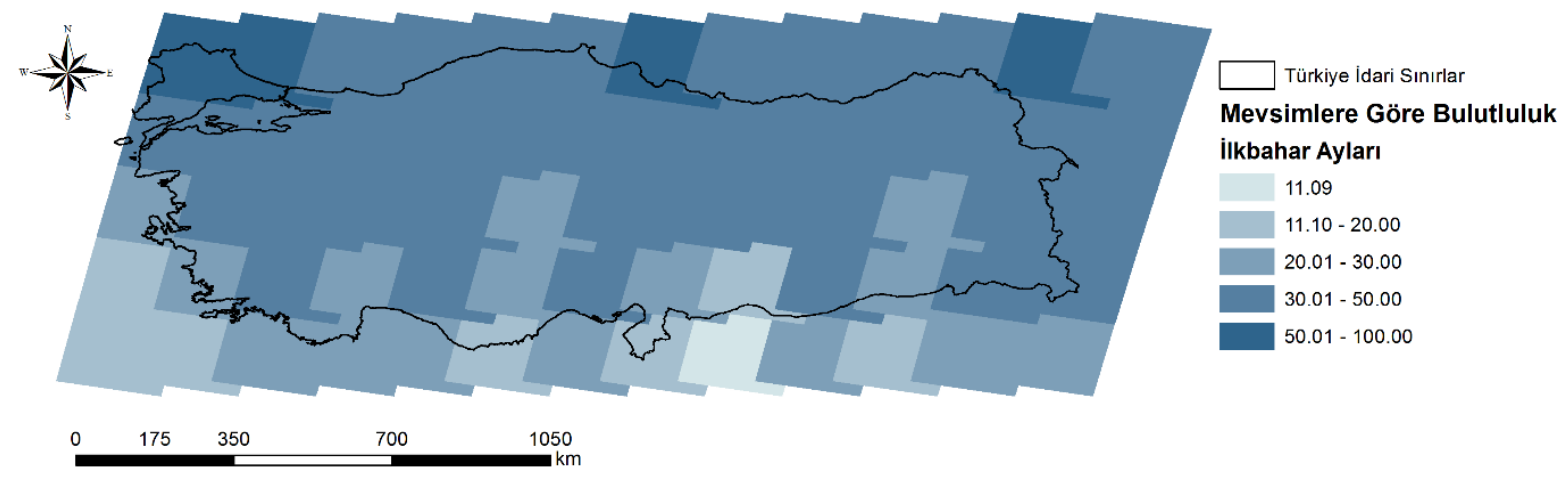

Şekil 4. İlkbahar ayları için ortalama bulutluluk haritası (2014-2016) (Landsat 8 görüntülerinden). 


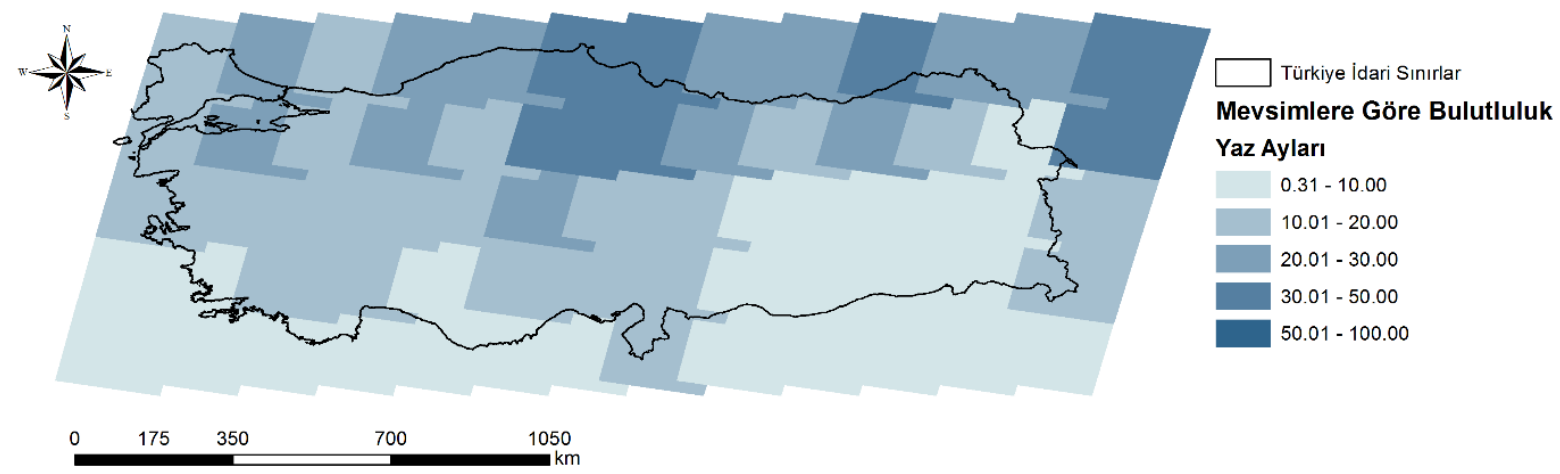

Şekil 5. Yaz ayları için ortalama bulutluluk haritası (2014-2016) (Landsat 8 görüntülerinden).

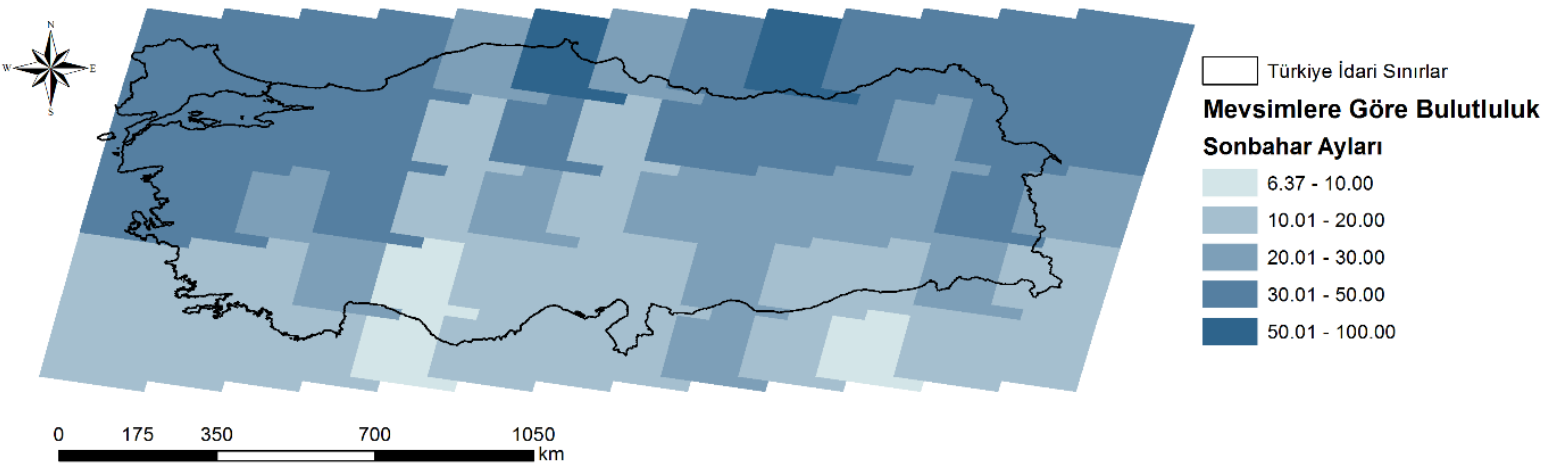

Şekil 6. Sonbahar ayları için ortalama bulutluluk haritası (2014-2016) (Landsat 8 görüntülerinden).

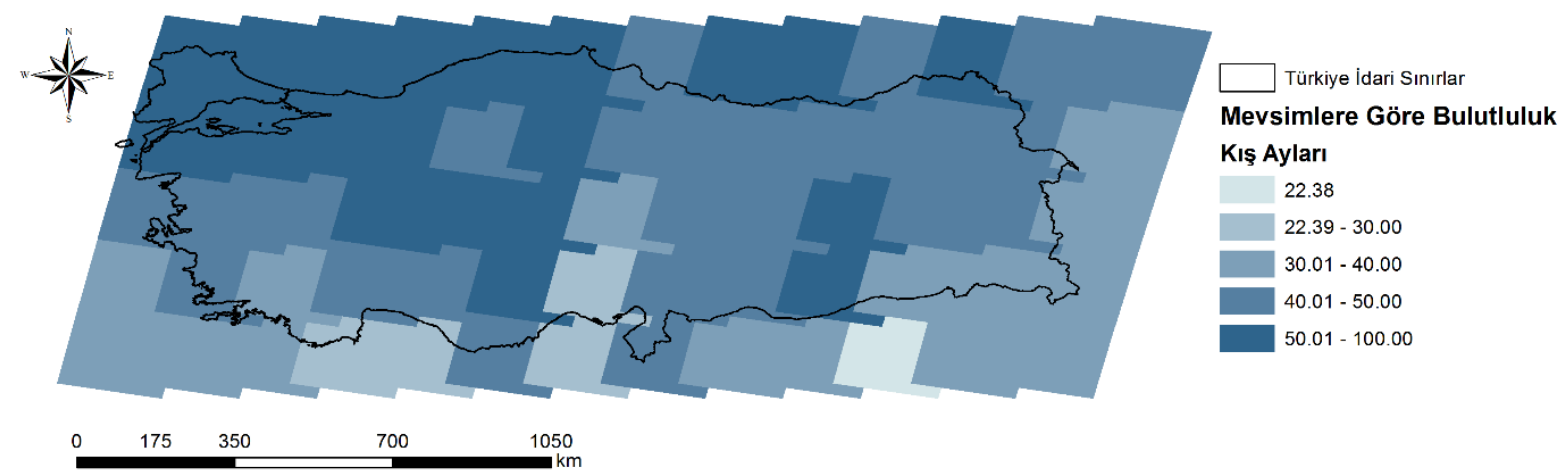

Şekil 7. Kış ayları için ortalama bulutluluk haritası (2014-2016) (Landsat 8 görüntülerinden).

Hesaba temel olan tüm görüntülerin ortalamasının alındığı 2014-2016 yılları Türkiye ortalama uydu görüntüsü bulutluluk haritası Şekil 8'de verilmiştir.

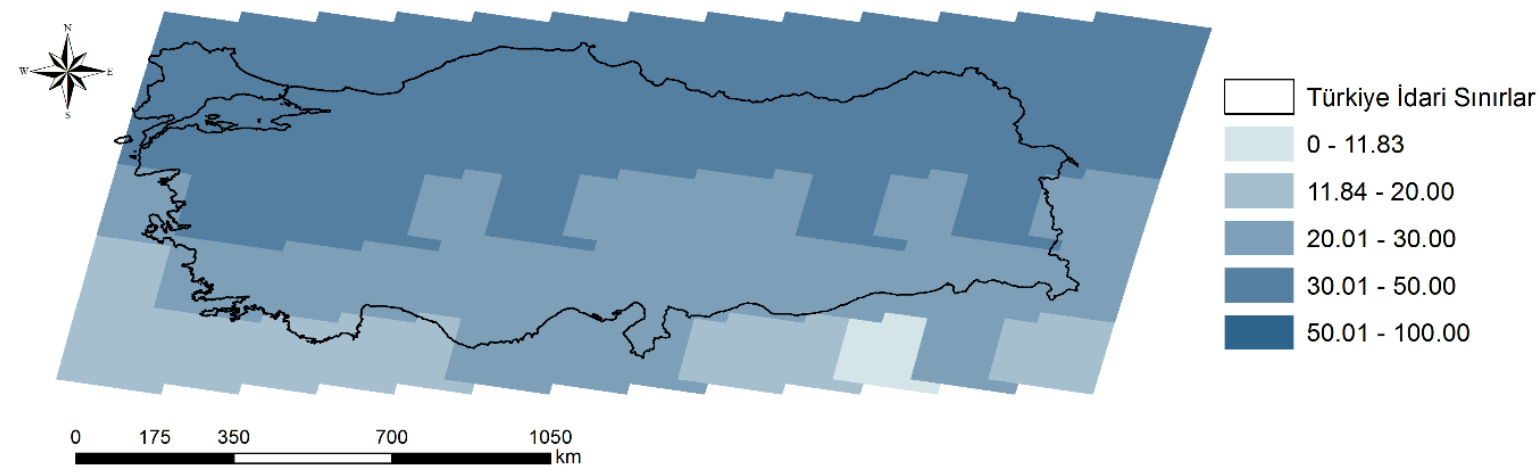

Şekil 8. Türkiye ortalama bulutluluk haritası (2014-2016) (Landsat 8 görüntülerinden). 


\section{SONUÇ}

$\mathrm{Bu}$ çalışmada, birçok uzaktan algılama çalışmasında temel veri hâline gelen Landsat ve Sentinel serisi uyduların Türkiye üzerinde çektiği görüntülerin ortalama bulutluk oranları farklı zaman dilimlerine göre değerlendirilmiştir. Tarımsal uzaktan algılama, su kirliliği vb. gibi uydu görüntü çekim tarihleri önem arzeden çalışmalarda hangi tarihlerde çekilen görüntülerin kullanılabilir olacağı üzerine bir yöntem önerilmiştir. Yapılan çalışma sonucunda 2014-2016 yılları arasında çekilen Landsat 8 ve Sentinel-2 görüntülerinin Türkiye genelinde ortalama bulutluluğu \%30.8 olarak hesaplanmıştır. İleride geçmişe yönelik tüm açık kaynaklı uydu görüntülerin bulutluluk oranlarının dahil edildiği ve sonuçlarında servis mimarisinde sunulacağı bir çalışma planlanmaktadır.

\section{KAYNAKLAR}

ESA, 2018, Level-2A Algorithm Overview, https://earth.esa.int/web/sentinel/technical-guides/sentinel-2$\mathrm{msi} /$ level-2a/algorithm, [01.08.2018]

Ju, J., Roy, D. P., 2008, The availability of cloud-free Landsat ETM+ data over the conterminous United States and globally. Remote Sensing of Environment, 112(3), 1196-1211.

Kalkan, K., Maktav, D. 2017, Segmentation Based Cloud and Cloud Shadow Detection in Satellite Imagery. Journal of Aeronautics and Space Technologies, 10(1), 45-54.

NASA, 2018, Harmonized Landsat Sentinel 2, https://hls.gsfc.nasa.gov/, [03.06.2018]

USGS, 2018, How is the percentage of cloud cover calculated in a Landsat scene?, https://landsat.usgs.gov/howpercentage-cloud-cover-calculated, [01.08.2018] 